được đặt ra. Các BN liệt gấp khuỷu không hoàn toàn có $11 \mathrm{BN}(12,2 \%)$ đã được điều trị vật lý, phục hồi chức năng trên 12 tháng nhưng sức cơ khổng cải thiện hơn nên đã được chỉ định phẫu thuật Steindler.

\section{KẾT LUẬN}

Qua nghiên cứu đặc điểm tổn thương trên lâm sàng của những bệnh nhân mất gấp khuỷu, chúng tôi nhận thây độ tuổi trung bình của các bệnh nhân nghiên cứu là $31,3 \pm 11,4$ tuổi, tổn thương mất gấp khuỷu chủ yếu xây ra ở nam giới. Nguyên nhân gây mất gấp khớp khuỷu hay gặp nhất là do tổn thương TK vận động làm mất chức năng cơ nhị đâu và cánh tay trước do tai nạn giao thông, cơ chế chính của tổn thương là do chấn thương gây căng dãn. Tổn thương chủ yếu xẩy ra bên trái, tổn thương thần kinh được phát hiện bằng phương pháp khám lâm sàng đơn thuần là chính $(90 \%)$, tổn thương chính là tổn thương loại II (70,0\%). Trước khi được phẫu thuật sức cơ gấp khuỷu của nhóm bệnh nhân nghiên cứu chủ yễu là sức cơ M0 $(87,7 \%)$.

\section{TÀI LIÊU THAM KHẢO}

1. Arvin R. Wali, David R. Santiago-Dieppa, Justin M. Brown and Ross Mandeville (2017) "Nerve transfer versus muscle transfer to restore elbow flexion after pan-brachial plexus injury: a cost-effectiveness analysis", Neurosurg Focus, Volume 43, pp. 1-2.

2. T. J. Quick, A. K. Singh, M. Fox, M. Sinisi, A. MacQuillan (2016) "A quantitative assessment of the functional recovery of flexion of the elbow after nerve transfer in patients with a brachial plexus injury", Bone Joint J, 98-B, pp. 517.

3. Alnot JY, Abols Y (1984), "Réanimation de la flexion du coudepar transferts tendineux dans les paralysies du plexus brachial de l'adulte", Rev Chir Orthop, pp. 313-323.

4. Rühmann O, Schmolke S, Gosse F, Wirth CJ (2002), "Transposition of local muscles to restore elbow flexion in brachial plexus palsy", Injury, pp. 597-609.

5. Monreal R (2007), "Steindler Flexorplasty to restore elbow flexion in C5-C6-C7 brachial plexus palsy type", J of brachial plexus and peripheral nerve injury, Pages 1-12.

6. Akira Wiberg, Michael Ng, Yasser Al Omran, Fidel Alfaro-Almagro, Pual McCathy, Jonathan Marchini, David L.Bennett, Stephen Smith Gwenaëlle Douaud and Dominic Furniss (2019) "Handedness, language areas and neuropsychiatric diseases: insights from brain imaging and genetics". J Brain, pp. 2938.

7. Brunelli GA, Vigasiol A, Brunelli GR (1995), "Modified Steindler procedure for elbow flexion restoration", J Hand Surg (16-A), pp. 743-746.

8. Brunelli GA, Brunelli GR (1991), "A fourth type of brachial plexus lesion: The intermediate (C7) palsy", J Hand Surg (16-B), pp. 492-495.

\title{
ĐÁNH GIÁ THỰC TRANG KIẾN THỨC, THÁI Độ VÀ HÀNH VI VỀ PHÒNG CHỐNG HIV/AIDS CỦA NGƯỜI DÂN 15-49 TUỔI TẠI TỈNH HẢI DƯƠ'NG NĂM 2020.
}

\author{
Nguyễn Thu Hà*, Lê Văn Thêm**, \\ Phạm Thị Nhuyên***, Trần Như Nguyên***, Phí Thị Nguyệt Thanh***, \\ Đinh Ngọc Sỹ ${ }^{* * *}$, Nguyễn Đức Sơn***, Nguyễn Thu Hà****
}

\section{TÓM TẮT}

Mục tiêu: Đánh giá thực trạng kiên thức, thái đô và hành vi của người dân trong độ tuổi 15-49 vể phòng chống HIV/AIDS tai tỉnh Hải Dương năm 2020. Đối tượng và phương pháp: Nghiên cứu mô tả cắt ngang 408 người dân trong độ tuổi từ 15- 49 hiện có hộ khẩu thường trú và đang sinh sống trên địa bàn tỉnh Hải Dương năm 2020. Kết quả và kết luận: Đánh giá thực trạng kiến thức về HIV/AIDS: Hầu hết

\footnotetext{
*Trường ĐH Khoa họ và Công Nghê HN.

**Trương ĐH Kỹ thuật Y tế Hải Dương;

***Trương Đai hoc Thành Đông

Chịu trách nhiệm chính: Phạm Thị Nhuyên

Email: nhuyenmd@yahoo.com.vn

Ngày nhận bài: 10/10/2021

Ngày phản biên khoa học: 5/11/2021

Ngày duyệt bài $15 / 11 / 2021$
}

$(85,2 \%)$ cho rằng đó là virus gây suy giảm miễn dịch ở người; Là bệnh truyền nhiểm $(9,5 \%)$ và là tệ nạn xã hội $(4,1 \%)$. Đánh giá thực trang thái độ và hành vi về HIV/AIDS: Có nhiêuu thái độ tích cực, gồm: Đa số $(50,5 \%)$ : sẵn sàng chăm sóc người bệnh tai nhà và đồng ý rằng người nhiễm HIV không phải thấy xấu hổ về bản thân mình; Nên cho người nhiêm HIV còn khỏe tiếp tục làm việc tại cộng đồng $(35,2 \%)$; Hầu hết (76\%) cho rằng có thể mua thức ăn của người bán hàng bị nhiễm HIV và đa số $(58,5 \%)$ cho rằng không nên giữ bí mật nếu có người trong gia đình bị nhiễ̂m HIV.Mốt số hành vi nguy cơ có thể lây nhiếm HIV/AIDS qua quan hệ tình dục (QHTD) và kiểu QHTD không an toàn ở cộng đồng, gồm: Quan hế với bạn tình ngoài vỡ/ chồng/ người yêu (15\%); Với gái mại dâm, khách làng chơi $(11,8 \%)$; Quan hệ tinh dục qua miệng - bộ phận sinh dục $(2,5 \%), \ldots$

Tư khóa: Kiến thức, thái độ, hành vi, người dân, phòng chống HIV/AIDS, Hải Dướng. 


\section{SUMMARY \\ ASSESSMENT OF THE STATUS OF KNOWLEDGE, ATTITUDE AND BEHAVIOR ON HIV/AIDS PREVENTION OF PEOPLE 15-49 YEARS OLD IN HAI DUONG PROVINCE IN 2020}

Objective: To assess the current status of knowledge, attitudes and behaviors of people aged 15-49 on HIV/AIDS prevention in Hai Duong province in 2020. Subjects and methods: A cross-sectional descriptive study of 408 people aged 15-49 who currently have permanent residence and are living in Hai Duong province in 2020. Results and conclusion: Assessment of the current status of knowledge about HIV/AIDS: Most (85.2\%) believe that it is human immunodeficiency virus; It is an infectious disease (9.5\%) and a society's vices (4.1\%). Assessing the actual status of attitudes about HIV/AIDS: There are many positive attitudes, including: Majority (50.5\%): ready to take care of the patient at home and agree that HIV-infected people do not have to feel ashamed. It is advisable to allow healthy HIV-infected people to continue working in the community $(35.2 \%)$; The majority $(76 \%)$ think that it is possible to buy food from an HIV-infected vendor and the majority (58.5\%) believe that it should not be kept a secret if someone in the family is infected with HIV. Assessment of behavior status on HIV/AIDS: Some risk behaviors that can transmit HIV/AIDS through sex and unsafe sex in the community, including: Sex with non-wife/partners/ husband/lover (15\%); with prostitutes and visitors (11.8\%); Oral sex - genitals $(2.5 \%)$...

Keywords: Knowledge, attitude, behavior, people, HIV/AIDS prevention, Hai Duong.

\section{I. ĐĂT VẤN ĐỀ}

HIV/AIDS là một đại dịch ảnh hưởng đến sức khỏe, kinh tế, văn hóa, xã hội, an ninh quốc gia, khu vực và của toàn cầu [1],[6]. Tại Việt Nam, qua hớn hai thập kỷ kể từ khi phát hiện ca nhiễm HIV đầu tiên (12/1990), tính đến 30/12/2012, toàn quốc đã phát hiện người nhiễm HIV tại 79\% xã/phường， $98 \%$ quận/huyện và $100 \%$ tỉnh/thành phố [3]. Theo số liệu thống kê của Cục phòng chống HIV/AIDS trực thuộc Bộ y tế, tính đến ngày $17 / 4 / 2013$ trên cả nước có 210.612 trường hợp nhiễm HIV/AIDS. Trong đó có 54.361 trường hợp đã chuyển sang giai đoạn AIDS và đã có 54.485 người tử vong [4]. Đại dịch HIV/AIDS không những gây tác hại đối với các nhóm hành vi nguy cơ cao mà còn lầy truyền cho nhóm người dễ bị tổn thương như phụ nữ và trẻ em [5], [7]. Cho đến nay, các hoạt động phòng chống HIV/AIDS đã được triển khai khá toàn diện, đã có hàng trăm nghiên cứu về lĩnh vực này [2].

Tại tînh Hải Dương, tính đến tháng 10/2018, lũy tích các trường hợp nhiễm HIV là người Hải
Dương được phát hiện trên địa bàn tỉnh là 4.680 người, trong đó 3.065 trường hợp chuyển sang giai đoạn AIDS, 1.676 trường hợp đã tử vong do AIDS. Tuy nhiên, cho đến nay, tỉnh Hải Dương chưa có nghiên cứu đầy đủ về phòng chống HIV/AIDS của người dân trong độ tuổi 15-49 nên chúng tôi tiến hành đề tài: "Đánh giá thực trạng kiến thức, thái độ và hành vi về phòng chống HIV/AIDS của người dân 15-49 tuổi tại tỉnh Hải Dương năm 2020". Nhằm mục tiêu:

1. Đánh giá thức trạng kiến thức của người dân trong độ tuổi 15-49 xác định đúng cách phòng ngưa lây nhiễm HIV/AIDS tại tỉnh Hải Dương năm 2020.

2. Đánh giá thực trạng thái độ và hành vi của người dân trong độ tuổi 15-49 đối với việc dự phòng lây nhiểm HIV/AIDS tại tỉnh Hải Dương năm 2020.

\section{II. ĐỐI TƯỢNG VÀ PHƯƠNG PHÁP NGHIÊN CỨU}

1. Đối tượng nghiên cứu: 408 người dân trong độ tuổi từ 15- 49, hiên có hộ khẩu thường trú và đang sinh sống trên địa bàn tỉnh Hải Dương năm 2020. Những người có tinh thần tỉnh táo và tự nguyện tham gia nghiên cứu. Mỗi địa điểm chọn 34 người tham gia nghiên cứu, như vậy đại diện của 12 huyện/Thị xã/Thành phố chọn được 408 người.

2. Thiết kế nghiên cứu: Nghiên cứu mô tả cắt ngang

3. Địa điểm nghiên cứu: Tỉnh Hải Dương

4. Thời gian nghiên cứu: Năm 2020

\section{KẾT QUẢ NGHIÊN CỨU}

1. Thông tin chung của đối tượng nghiên cứu 1.1. Phân bố về giới

\begin{tabular}{|c|c|c|}
\hline Tình trạng giới tính & $\mathbf{n}$ & Tỷ lệ \% \\
\hline Nam & 206 & 50.4 \\
\hline Nữ & 202 & 49.6 \\
\hline Tống & $\mathbf{4 0 8}$ & $\mathbf{1 0 0}$ \\
\hline
\end{tabular}

Nhân xét: Tỷ lệ nam tham gia nghiên cứu $(50,4 \%)$ cao hơn nữ $(49,6 \%)$.

\subsection{Tình trạng hôn nhân}

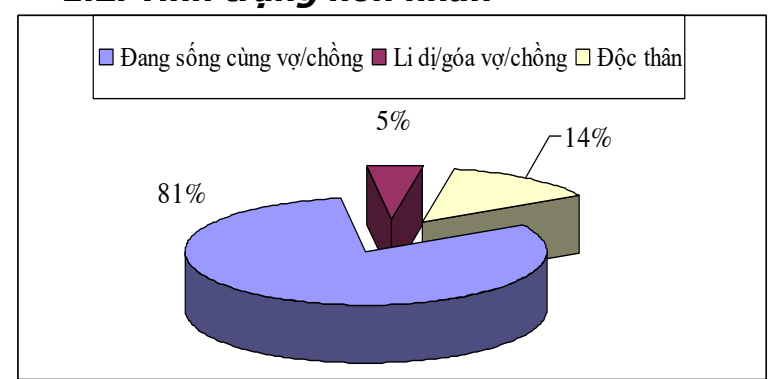

Nhận xét: Hầu hết đã có gia đình (81\%); Tiếp đến là người sống độc thân (14 \%) và thấp 
nhất (5\%) là đối tượng ly dị/góa.

\subsection{Phân bố theo nhóm tuổi.}

\begin{tabular}{|c|c|c|}
\hline Nhóm tuối & $\mathbf{n}$ & Tỷ lệ $\%$ \\
\hline Từ $15-24$ tuối & 7 & 1.7 \\
\hline Từ $25-35$ tuối & 273 & 66.3 \\
\hline Từ $36-49$ tuối & 128 & 32.0 \\
\hline Tống cộng & $\mathbf{4 0 8}$ & $\mathbf{1 0 0}$ \\
\hline
\end{tabular}

Nhận xét: Nhóm tuối 25-35 chiếm tỷ lệ cao nhất $(66.3 \%)$ và nhóm tuổi $15-24$ chiếm tỷ lệ thấp nhất (1.7\%).

\subsection{Phân bố về trình độ học vấn.}

\begin{tabular}{|c|c|c|}
\hline Học vấn & $\mathbf{n}$ & Tỷ lệ \% \\
\hline Chưa biết chữ & 1 & 0,2 \\
\hline Học hết tiếu học (cấp 1) & 125 & 30,6 \\
\hline Học hết PTCS (cấp 2) & 244 & 59,9 \\
\hline Học hết PTTH (cấp 3) & 20 & 4,9 \\
\hline $\begin{array}{c}\text { Đại học/trên đại học } \\
\text { hoặc tương đương }\end{array}$ & 18 & 4,4 \\
\hline Tống cộng & $\mathbf{4 0 8}$ & $\mathbf{1 0 0}$ \\
\hline
\end{tabular}

Nhânn xét: Hầu hết có trình độ học vấn ở bậc tiểu học $(30,6 \%)$ và Trung học cơ sở $(59,9 \%)$. Có rất ít thuộc trình độ Trung học phổ thông $(4,4 \%)$.

1.5. Phân bố theo địa bàn sinh sống.

\begin{tabular}{|c|c|c|}
\hline Đià bàn & $\mathbf{n}$ & Tỷ lệ \% \\
\hline Thành phố & 136 & 33,4 \\
\hline Nông thôn & 272 & 66,6 \\
\hline Tống cộng & $\mathbf{4 0 8}$ & $\mathbf{1 0 0}$ \\
\hline
\end{tabular}

Nhận xét: Hai phần ba trong số họ sống tại nông thôn $(66,6 \%)$ và chỉ có một phần ba là sống tại thành phố (33,4\%).

1.6. Phân bố về thời gian sinh sông tại tỉnh Hải Dương.

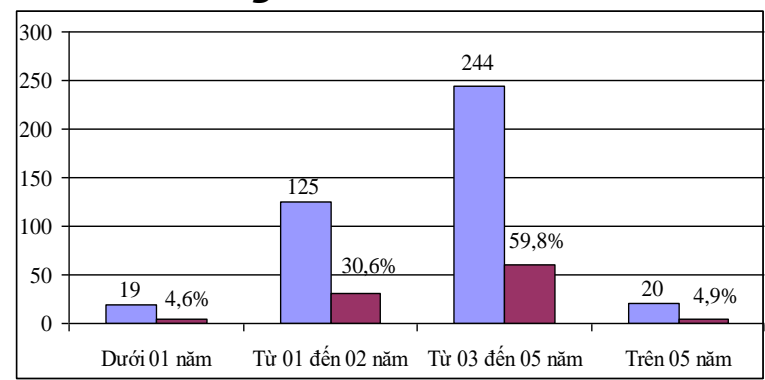

Nhận xét: Hầu hết họ đã sống tỉnh Hải Dương từ $1-2$ năm $(30,6 \%)$ và từ $3-5$ năm (59,8\%). Tỷ lệ rất thấp sống tại tỉnh Hải Dương dưới 1 năm $(4,6 \%)$ và trên 5 năm $(4,9 \%)$.

2. Thực trang kiến thức của người dân trong độ tuổi 15-49 xác định đúng cách phòng ngừa lây nhiễm HIV/AIDS.

2.1. Thực trạng kiến thức về lây nhiễm virus HIV.

2.2.1 Hiểu biết chung về virus HIV

\begin{tabular}{|c|c|c|}
\hline \multirow{2}{*}{ Nhóm kiến thức } & \multicolumn{2}{|c|}{ Kết quả } \\
\cline { 2 - 3 } & $\mathbf{n}$ & Tỷ lệ \% \\
\hline $\begin{array}{c}\text { Là virus gây suy giảm } \\
\text { miễn dịch ở người }\end{array}$ & 351 & 85,2 \\
\hline Là tên nạn xã hội & 17 & 4,1 \\
\hline Là bệnh truyền nhiềm & 39 & 9,5 \\
\hline Không biết & 1 & 0,2 \\
\hline Tống cộng & $\mathbf{4 0 8}$ & $\mathbf{1 0 0}$ \\
\hline
\end{tabular}

Nhận xét: Hầu hết $(85,2 \%)$ có quan niệm đúng về HIV là virus gây suy giảm miến dịch ở người.

2.2.2 Hiểu biết về yếu tố nguy cơ lây nhiễm HIV.

\begin{tabular}{|c|c|c|}
\hline Nhóm kiến thức & \multicolumn{2}{|c|}{ Kết quả } \\
\cline { 2 - 3 } & $\mathbf{n}$ & Tỷ lệ $\%$ \\
\hline Người tiêm chích ma túy & 80 & 19,5 \\
\hline Người hành nghề mại dâm & 52 & 12,5 \\
\hline Nam quan hệ đồng tính (nam giới với nam giới) & 23 & 5,6 \\
\hline Cả 3 đối tượng trên & 172 & 41,7 \\
\hline Tất cả mọi người đều có thể bị lây nhiềm HIV/AIDS. & 57 & 13,8 \\
\hline Không biết & 24 & 5,8 \\
\hline Tổng cộng & $\mathbf{4 0 8}$ & $\mathbf{1 0 0}$ \\
\hline
\end{tabular}

Nhận xét: Hầu hết họ cho rằng yếu tố nguy cơ lây nhiếm HIV/AIDS, gôm: Người tiêm chích ma


mọi người đều có thể bị lây nhiễm HIV/AIDS $(13,8 \%)$. Tuy nhiên, vẩn còn một số $(5,8 \%)$ ít không biết những yếu tố nguy cơ có thể lây nhiễm HIV/AIDS.

2.2.3 Hiểu biết về các nhóm kiến thức liên quan đến lây nhiễm HIV.

\begin{tabular}{|c|c|c|}
\hline \multicolumn{1}{|c|}{ Nhóm kiến thức } & \multicolumn{2}{|c|}{ Trả lời đúng } \\
\cline { 2 - 3 } & $\mathbf{N}$ & $\mathbf{\%}$ \\
\hline Dùng chung/dùng lại bơm kim tiên có thể bị lây nhiểm HIV & 283 & 68,7 \\
\hline $\begin{array}{c}\text { Sứ dụng bao cao su trong tất cả các lần quan hệ tình dục có thể phòng tránh } \\
\text { lây nhiếm HIV }\end{array}$ & 388 & 94,2 \\
\hline Sống chung thùy thì có thể phòng tránh HIV & 385 & 93,4 \\
\hline
\end{tabular}




\begin{tabular}{|c|c|c|}
\hline Một người trông khỏe mạnh có thể mang virut HIV & 265 & 64,3 \\
\hline Một người trông khỏe mạnh có thế mang virut HIV & 265 & 64,3 \\
\hline HIV có thể lây từ mẹ sang con lúc mang thai, đẻ, khi cho bú & 401 & 97,3 \\
\hline Có thuốc điều trị cho me nhiếm HIV đế giảm lây truyền sang con & 334 & 81,1 \\
\hline Đã có thuốc điều trị HIV đế giúp người nhiếm khỏe hơn hoặc sống lâu hơn & 314 & 76,2 \\
\hline
\end{tabular}

Nhận xét: Hiểu biết đúng của đối tượng nghiên cứu về các nhóm kiến thức liên quan đến lây nhiễm HIV ở mức cao (64.3\%) và rất cao 97,3\%).

2.2. Thực trạng kiến thức về bệnh AIDS.

2.2.1 Hiểu biết về các nhóm kiến thức liên quan đến lây nhiếm bệnh AIDS.

\begin{tabular}{|c|c|c|}
\hline Nhóm kiến thức & \multicolumn{2}{|c|}{ Trả lời đúng } \\
\cline { 2 - 3 } & $\mathbf{N}$ & Tỹ lệ \% \\
\hline AIDS là một tệ nạn xã hội & 29 & 7,1 \\
\hline AIDS là bệnh nan y hiện không có thuốc chữa khỏi & 170 & 41,7 \\
\hline Là hội chứng suy giảm miến dịch mắc phải ở người & 87 & 21,3 \\
\hline AIDS là bệnh dịch nguy hiếm hiện nay. & 122 & 29,9 \\
\hline Tổng cộng & $\mathbf{4 0 8}$ & $\mathbf{1 0 0 , 0}$ \\
\hline
\end{tabular}

Nhận xét: Hiểu biết đúng về các nhóm kiến thức liên quan đến lây nhiếm bệnh AIDS chưa cao: chỉ từ 7,1\% (AIDS là một tệ nạn xã hội) đến 41,7\% (AIDS là bệnh nan y hiện không có thuốc chữa khỏi).

\subsubsection{Hiểu biêt đứng nhóm kiến thức về bênh AIDS}

\begin{tabular}{|c|c|c|}
\hline Nhóm kiến thức & \multicolumn{2}{|c|}{ Trả lời đúng } \\
\cline { 2 - 3 } & $\mathbf{n}$ & $\mathbf{\%}$ \\
\hline Dựa vào các dấu hiệu như: Sút cân, gây yếu, các bệnh trên da, ... & 372 & 90,3 \\
\hline $\begin{array}{c}\text { Ngườ đó là người nghiện chích ma túy, mại dâm hoặc là người có quan hệ } \\
\text { đồng giới nam. }\end{array}$ & 265 & 64,3 \\
\hline Dựa vào xét nghiệm HIV & 382 & 92,7 \\
\hline Không biết & 0 & 0 \\
\hline
\end{tabular}

Nhận xét: Hiểu biết đúng của đối tượng nghiên cứu về các nhóm kiến thức liên quan đến bệnh AIDS ở mức cao $(64.3 \%)$ và rất cao $92,7 \%)$.

3. Thực trạng hành vi thực hành phòng ngừa lây nhiễm HIV/AIDS của người dân trong độ tuổi 15-49.

3.1. Phân bố tỷ lệ dùng bao cao su trong QHTD

\begin{tabular}{|c|c|c|}
\hline Nội dung & $\mathbf{n}$ & $\mathbf{\%}$ \\
\hline Không bao giờ sử dụng & 99 & 24,3 \\
\hline Thỉnh thoảng mới sự dụng & 61 & 15,0 \\
\hline Thường xuyên sử dụng không đúng cách & 148 & 36,3 \\
\hline Thường xuyên sử dụng đúng cách: & 100 & 24,4 \\
\hline Tống cộng & $\mathbf{4 0 8}$ & $\mathbf{1 0 0}$ \\
\hline
\end{tabular}

Nhận xét: Trong QHTD, chỉ có 24,4\% có hành vi thực hành đúng khi dùng bao cao su. Còn nhiêu hành vi thực hành tiêu cực góp phần làm gia tăng nguy cơ lây nhiễm HIV/AIDS, như: Không bao giờ sử dụng (24,3\%); Thỉnh thoảng mới sử dụng (15\%) và Thường xuyên sử dụng không đúng cách (36\%).

\subsection{Hành vi thực hành đúng đôii với với bệnh nhân AIDS}

\begin{tabular}{|c|c|c|}
\hline \multirow[t]{2}{*}{ Nhóm kiến thức } & \multicolumn{2}{|c|}{$\begin{array}{c}\text { Kết quả } \\
\text { trả lời đúng }\end{array}$} \\
\hline & $\mathbf{n}$ & $\%$ \\
\hline Không giữ bí mật nếu có người trong gia đình bị nhiềm HIV & 37 & 9,0 \\
\hline Sằn sàng chăm sóc người thân nhiếm HIV/AIDS tại nhà & 366 & 88,8 \\
\hline Nên cho người thân nhiếm HIV còn khỏe mạnh tiếp tục lao động sản xuất & 331 & 80,3 \\
\hline Có thể mua thức ăn, mua hàng hóa của những người bị nhiểm HIV/AIDS & 237 & 57,5 \\
\hline Người nhiềm HIV không phải thấy xấu hố về bản thân mình & 200 & 48,5 \\
\hline Người nhiểm HIV là người có lối vì là người mang bệnh tật cho cộng đồng & 360 & 87,4 \\
\hline $\begin{array}{l}\text { Tất cả những người ở cộng đồng phải làm xét nghiệm HIV, và phải công bố } \\
\text { kết quả cho người cưng gia đình biết tình trạng nhiếm HIV của mình }\end{array}$ & 189 & 45,9 \\
\hline
\end{tabular}


Khi bị nhiểm HIV/AIDS thôn/khu dân phải cho người đó sống biệt lập, hoặc làm riêng chỗ khác để tránh lây nhiễm cho mọi người

Nhận xét: Có nhiều hành vi tích cực đối với bệnh nhân HIV/AIDS ở mức rất cao, trong đó $88,8 \%$ sẵn sàng chăm sóc người thân nhiễm HIV/AIDS tại nhà hoặc $80,3 \%$ cho rằng nên cho người nhiếm HIV khỏe mạnh tiếp tục lao động sản xuất.

3.3. Hành vi thực hành và nguy cơ có thể lây nhiếm HIV/AIDS trong quan hệ tình dục và kiểu (QHTD) không an toàn ở cộng đồng.

\begin{tabular}{|c|c|c|}
\hline Đối tượng và kiểu QHTD trong 12 tháng qua & $\mathbf{n}$ & $\mathbf{\%}$ \\
\hline Vợ/chồng/người yêu & 199 & 48,8 \\
\hline Bạn tình (ngoài vợ/chông/người yêu) & 61 & 15,0 \\
\hline Gái mại dâm, khách làng chơi & 48 & 11,8 \\
\hline Bị cưỡng phải quan hệ tình dục ngoài ý muốn & 5 & 1,2 \\
\hline Quan hệ tinh dục qua miệng - bộ phận sinh dục & 10 & 2,5 \\
\hline Quan hệ tinh dục kiếu thủ dâm - dùng tay khích thích để xuất tinh ra ngoài & 15 & 3,7 \\
\hline Không QHTD (chưa biết) & 70 & 17,2 \\
\hline Tổng cộng & $\mathbf{4 0 8}$ & $\mathbf{1 0 0}$ \\
\hline
\end{tabular}

Nhận xét: Đa số có QHTD với vợ/chồng/ người yêu $(48,8 \%)$ và bạn tình $(15 \%)$. Tuy nhiên, còn có hành vi QHTD không lành mạnh góp phần làm gia tăng nguy cơ lây nhiễm HIV/AIDS, như: QHTD vơi gái mại dâm, khách làng chơi $(11,8 \%)$; Quan hệ tinh dục qua miệng - bộ phận sinh dục $(2,5 \%)$ hoăc bị cưỡng phải quan hệ tình dục ngoài ý muốn $(1,2 \%)$, ..

\section{BÀN LUẦN}

1. Thông tin chung của đối tượng nghiên cứu. Đánh giá thực trạng kiến thức, thái độ, hành vi về phòng chống HIV/AIDS và tìm ra những yếu tố nguy cơ lây nhiễm HIV/AIDS trong độ tuổi 15- 49 của 408 người dân tại tỉnh Hải Dương năm 2020, trong đó tỷ lệ nam $(50,4 \%)$ cao hơn nữ (49,6\%). Nhóm tuổi 25-35 chiếm tỷ lệ cao nhất $(66.3 \%)$ và nhóm tuổi $15-24$ chiếm tỷ lệ thấp nhất (1.7\%). Hầu hết đã có gia đình (81\%); Tiếp đến là người sống độc thân (14 \%) và rất ít $(5 \%)$ là đối tượng ly dị/góa. Hầu hết có trình độ học vấn ở bậc tiểu học $(30,6 \%)$ và Trung học cơ sở $(59,9 \%)$. Có rất ít trong số họ có trình độ Trung học phổ thông $(4,4 \%)$. Hai phần ba trong số họ sống tại nông thôn $(66,6 \%)$ và chỉ có một phần ba là sống tại thành phố $(33,4 \%)$. Hầu hết,đã sống tỉnh Hải Dương từ 1-2 năm $(30,6 \%)$ và từ $3-5$ năm $(59,8 \%)$. Có tỷ lệ rất thấp sống tại tỉnh Hải Dương dưới 1 năm $(4,6 \%)$ và trên 5 năm $(4,9 \%)$.

2. Thực trang kiến thức của người dân trong độ tuổi 15-49 xác định đúng cách phòng ngừa lây nhiễm HIV/AIDS.

2.1 Hiểu biết chung về virus HIV: Hầu hết $(85,2 \%)$ có quan niệm đúng về HIV là virus gây suy giảm miễn dịch ở người. Hầu hết họ cho rằng yếu tố nguy cơ lây nhiễm HIV/AIDS, gồm:

Người tiêm chích ma túy $(19,5 \%)$; Người hành nghề mại dâm (12,5\%); Nam quan hệ đồng tính $(5,6 \%)$ và tất cả mọi người đều có thể bị lây nhiễm HIV/AIDS (13,8\%). Tuy nhiên, vẫn còn một số $(5,8 \%)$ ít không biết những yếu tố nguy cở có thể lây nhiễm HIV/AIDS. Hiểu biết đúng của đối tượng nghiên cứu về các nhóm kiến thức liên quan đến lây nhiễm HIV/AIDS ở mức cao $(64.3 \%)$ và rất cao 97,3\%).

2.2 Thực trạng kiến thức về bệnh AIDS: Hiểu biết đứng về các nhóm kiến thức liên quan đến lây nhiễm bệnh AIDS chưa cao: chỉ từ 7,1\% (AIDS là một tệ nạn xã hội) đến 41,7\% (AIDS là bệnh nan y hiện không có thuốc chữa khỏi). Hiểu biết đúng của đối tượng nghiên cứu về các nhóm kiến thức liên quan đến bệnh AIDS ở mức cao $(64.3 \%)$ và rất cao $92,7 \%)$.

3. Thực trang hành vi thực hành phòng ngừa lây nhiểm HIV/AIDS của người dân trong độ tuổi 15-49.

3.1. Hành vi thực hành đúng đối với với bệnh nhân AIDS: Có nhiều hành vi tích cực đối với bệnh nhân HIV/AIDS ở mức rất cao, trong đó $88,8 \%$ sẵn sàng chăm sóc người thân nhiễm HIV/AIDS tại nhà hoặc $80,3 \%$ cho rằng nên cho người nhiếm HIV còn khỏe mạnh tiếp tục lao động sản xuất.

3.2. Phân bố tỷ lệ dùng bao cao su trong QHTD: Trong QHTD, chỉ có $24,4 \%$ có hành vi thực hành đúng khi dùng bao cao su. Còn nhiều hành vi thực hành tiêu cực góp phần làm gia tăng nguy cơ lây nhiễm HIV/AIDS, như: Không bao giờ sử dụng (24,3\%); Thỉnh thoảng mới sử dụng $(15 \%)$ và Thường xuyên sử dụng không đúng cách (36\%).

3.3. Hành vi thực hành và nguy cơ có thể lây nhiếm HIV/AIDS trong quan hệ tình 
dục và kiểu (QHTD) không an toàn ở cộng đồng: Kết quả tích cực là đa số có QHTD với vợ/chồng/người yêu $(48,8 \%)$ và bạn tình $(15 \%)$. Tuy nhiên, còn có hành vi QHTD không lành mạnh góp phần làm gia tăng nguy cơ lây nhiễm HIV/AIDS, như: QHTD vơi gái mại dâm, khách làng chơi (11,8\%); QHTD qua miệng $(2,5 \%)$ hoặc bị cưỡng phải QHTD ngoài ý muốn $(1,2 \%)$.

\section{KẾT LUẦN}

1. Thông tin chung của đối tượng nghiên cứu. Với cõ̃ mẫu 408 người dân tại tỉnh Hải Dương năm 2020 ở độ tuổi 15- 49 được đánh giá về kiến thức, thái độ, hành vi về phòng chống HIV/AIDS và tìm ra những yếu tố nguy cơ lây nhiếm HIV/AIDS. Không có sự khác biệt lớn về giới tính giữa nam $(50,4 \%)$ và nữ $(49,6 \%)$. Nhóm tuổi $25-35$ chiếm tỷ lê cao nhất $(66.3 \%)$ và nhóm tuổi 15-24 chiếm tỷ lệ thấp nhất (1.7\%). Hầu hết đã có gia đình $(81 \%)$. Hầu hết có trình độ học vấn ở bậc tiểu học $(30,6 \%)$ và Trung học cơ sở (59,9\%). Đa số họ sống tại nông thôn $(66,6 \%)$ còn lại sống ở thành phố (33,4\%). Thời gian sinh sống tại Hải Dương còn ngắn: Từ 1-2 năm $(30,6 \%)$ và từ $3-5$ năm $(59,8 \%)$; Dưới 1 năm $(4,6 \%)$ và trên 5 năm $(4,9 \%)$.

2. Thực trang kiến thức của người dân trong độ tuổi 15-49 về phòng ngừa lây nhiễm HIV/AIDS tương đối tốt: Có quan niệm đúng về HIV là virus gây suy giảm miên dịch ở người. Họ cho rằng yếu tố nguy cơ lây nhiễm HIV/AIDS, gồm: Người tiêm chích ma túy $(19,5 \%) ; \quad$ Người hành nghề mại dâm $(12,5 \%)$; Nam quan hệ đồng tính $(5,6 \%), .$. Hiểu biết đúng về các nhóm kiến thức liên quan đến lây nhiễm HIV/AIDS ở mức cao (64.3\%) và rất cao $97,3 \%)$. Tuy nhiên, vẫn còn một số $(5,8 \%)$ không biết những yếu tố nguy cơ có thể lây nhiễm HIV/AIDS.

2.2 Thực trạng kiến thức về bệnh AIDS: Hiểu biết đứng về các nhóm kiến thức liên quan đến lây nhiễm bệnh AIDS chưa cao: chỉ từ 7,1\% (AIDS là một tệ nạn xã hội) đến 41,7\% (AIDS là bệnh nan y hiện không có thuốc chữa khỏi). Hiểu biết đúng của đối tượng nghiên cứu về các nhóm kiến thức liên quan đến bệnh AIDS ở mức cao (64.3\%) và rất cao 92,7\%).

3. Thực trang hành vi thực hành phòng ngừa lây nhiềm HIV/AIDS của người dân trong độ tuổi 15-49.

3.1 Hành vi thực hành đúng đối với với bênhh nhân AIDS: Có nhiều hành vi tích cực đối với bệnh nhân HIV/AIDS: $88,8 \%$ sẵn sàng chăm sóc người thân nhiễm HIV/AIDS tại nhà; $80,3 \%$ nên cho người nhiễm HIV còn khỏe mạnh tiếp tục lao động sản xuất.

3.2 Phân bố tỷ lệ dùng bao cao su trong QHTD: Trong QHTD, chỉ có $24,4 \%$ có hành vi thực hành đúng khi dùng bao cao su. Nhiều hành vi tiểu cực góp phần làm gia tăng nguy cơ lây nhiễm HIV/AIDS, như: Không bao giờ sử dụng $(24,3 \%)$; Thỉnh thoảng mới sử dụng (15\%) và Thường xuyên sử dụng không đúng cách (36\%).

3.3 Hành vi thực hành và nguy cơ có thể lây nhiễm HIV/AIDS trong QHTD và kiểu QHTD không an toàn ở cộng đồng: Đa số có QHTD với vợ/chồng/người yêu $(48,8 \%)$ và bạn tình (15\%). Tuy nhiên, còn có hành vi QHTD không lành mạnh góp phần làm gia tăng nguy cơ lây nhiễm HIV/AIDS, như: QHTD vơi gái mại dâm, khách làng chơi (11,8\%); QHTD qua miệng $(2,5 \%)$ hoặc bị cưỡng phải QHTD ngoài ý muốn $(1,2 \%)$, ..

\section{KIẾN NGH!}

1. Cần sử dụng mô hình can thiệp truyền thông dựa vào cộng đồng thông qua mạng lưới y tế cơ sở, mạng lưới cộng tác viên, tuyên truyền viên, giáo dục viên đồng đẳng để tăng cường kiến thức, thái độ, hành vi tích cực và hạn chế, triệt tiêu những kiến thức, thái độ hành vi tiêu cực về phòng chống HIV/AIDS.

2. Cần có các nghiên cứu tiếp theo về một số mô hình can thiệp dựa vào cộng đồng về phòng chống HIV/AIDS của người dân 15-49 tuổi tại tỉnh Hải Dương để chứng minh rõ hiệu quả và tính bền vững của các giải pháp can thiệp

\section{TÀI LIỆU THAM KHẢO}

1. Bộ Y tế (2010), Báo cáo 20 năm hoạt động phòng, chống HIV/AIDS, tr.107-108.

2. Bộ Y tế (2010), Các công trình nghiên cứu khoa học về HIV/AIDS giai đoạn 2006 - 2010 Hà Nội, tr.742, 743.

3. Bộ Y tế (2013), Báo cáo kết quả hoạt động phòng, chông HIV/AIDS năm 2012 và định hưởng kế hoạch năm 2013, Hà Nội.

4. Cưc Phòng Chống HIV/AIDS-Bộ Y Tế. Báo cáo sổ 796/BC-BYT ngày17/4/2013.

5. Nguyến Anh Tuân, Nguyễn Thị Thanh Hà, Bùi Đức Thẳng và cộng sự (2010), "Tỳ lệ nhiếm HIV, Giang mai và các yếu tố hành vi nguy cơ lây nhiềm HIV trong nhóm đồng bào dân tộc ít người tại Việt Nam", Tap chí y hoc thực hành, $(742+743)$, tr. 29-39.

6. UNAIDS (2001), Reaching regional on improved behavioral and sero surveillance for HIV, Regional conference in East Africa, UNAIDS Best Practice Collection

7. UNAIDS Report on Global AIDS epidemic 2012 (2012), http://www.unaids.org/en/media/ unaids/contentassets/documents/epidemiol ogy/2012/gr2012/20121120_UNAIDS_Global_Repo rt_2012_with_annexes en.pdf. 